\title{
Biomarkers and Mortality in ST-Segment Elevation Myocardial Infarction
}

Pedro Pimenta de Mello Spineti ${ }^{1,2}$

Hospital Universitário Pedro Ernesto, ${ }^{1}$ Rio de Janeiro, RJ - Brazil

Hospital Unimed - Rio, ${ }^{2}$ Rio de Janeiro, RJ - Brazil

Biomarkers have been increasingly used in non-STsegment elevation acute coronary syndromes (NSTEACS) for diagnosis, stratification, and short-and longterm prognosis. ${ }^{1}$ However, they play a less decisive role in ST-segment elevation myocardial infarction (STEMI) where ST-segment elevation in ECG remains the most important tool for diagnosis and treatment decision. ${ }^{2}$

Troponin has been the most widely used biomarker to evaluate the prognosis in STEMI, ${ }^{1}$ but other biomarkers may also be used to assess the potential causes and complications of myocardial infarction (MI). ${ }^{3}$ High sensitivity C-reactive protein (hs-CRP) is substantially increased in STEMI as a result of the inflammatory response to myocyte necrosis, and is associated with the subsequent risk for death or heart failure. ${ }^{4-6}$ Natriuretic peptides reflect the hemodynamic impact of MI and are associated with its prognosis. ${ }^{7}$ Although both natriuretic peptides and CRP enhance risk assessment, no clear guidance is available on how to direct specific therapeutic maneuvers in the setting of STEMI based on these biomarkers. ${ }^{3}$

Damman et al. ${ }^{8}$ studied the role of multiple biomarkers in a large cohort of STEMI patients. Glucose, estimated glomerular filtration rate (eGFR), and N-terminal probrain natriuretic peptide (NT-ProBNP), but not hs-CRP were the strongest predictors for long-term mortality in 1,034 STEMIs. ${ }^{8}$

Correia and Esteves ${ }^{9}$ performed a systematic review and meta-analysis on C-reactive protein and outcomes in acute coronary syndromes. After literature review, 19 articles were included in the study, most of them

\section{Keywords}

ST- Elevation Myocardial Infarction / mortality; Biomarkers; C Reactive Protein. addressing NSTEMI and unstable angina. In the analysis of short-term outcomes, nine studies were positive and six were negative, with an overall OR of 1.65 (95\% CI: 1.22.3). Nevertheless, overall multivariate OR of short-term follow-up was not obtained, since this measurement was described only in three heterogeneous studies. Only two short-term studies analyzed the incremental predictive value of CRP in relation to multivariate models, with contrasting results.

A study published in this issue by Milano et al., ${ }^{10}$ addresses the role of hs-CRP on in-hospital mortality in a single center in Brazil. A total of 118 patients admitted for STEMI in the emergency department or cardiac intensive care unit were included in a retrospective cohort study. Serum hs-CRP was measured at admission. Twenty patients (16.9\%) died during hospitalization. Admission hs-CRP levels were higher among the patients who died (median 10.47 [IQR 23.99]) compared with those who survived (median 2.13 [IQR 5.66]). Binary logistic regression analysis revealed that in-hospital death was independently associated with higher concentration of hs-CRP and older age. A one-unit increase in hs-CRP increased the risk of death by $15 \%$, after adjustment for established risk factors.

The research question studied by Milano et al. ${ }^{10}$ seems relevant and the results contribute to the knowledge on prognostic factors in STEMI. However, the study has limitations and the findings should be interpreted with caution. It was a single- center retrospective study with a small sample, which could limit its external validity. In addition, the study did not establish a cut-off point for hs-CRP levels in relation to mortality, making it hard to interpret the assay results in clinical practice. The multivariate model did not include other known prognostic variables such as the Killip class, ${ }^{11} \mathrm{MI}$ location, time to treatment, and cardiac arrest at admission. Also, the authors did not analyze the incremental value of hs-

Mailing Address: Pedro Pimenta de Mello Spineti

Boulevard 28 de setembro, 77. Postal Code: 20551-030, Vila Isabel, Rio de Janeiro, RJ - Brazil.

E-mail: pedrospineti@yahoo.com.br, pedrospineti@gmail.com

DOI: 10.5935/2359-4802.20190013 
CRP to usual prognostic score systems in STEMI, such as GRACE ${ }^{12}$ and TIMI Risk ${ }^{13}$ scores. Another major issue is the absence of new treatments directly addressing hsCRP in STEMI. ${ }^{3}$

Despite these biases and limitations, we believe the study has some merits. The findings suggest that hs-CRP levels can be used as a measure of inflammatory response to myocardial ischemia after STEMI, which could lead to

\section{References}

1. Biasucci LM, Della Bona R. Prognostic Biomarkers in ST-Segment Elevation Myocardial Infarction. J Am Coll Cardiol. 2011;57(1):37-9.

2. Piegas LS, Timerman A, Feitosa GS, Nicolau JC, Mattos LAP, Andrade MD, et al. V Diretriz da Sociedade Brasileira de Cardiologia sobre Tratamento do Infarto Agudo do Miocárdio com Supradesnível do Segmento ST. Arq Bras Cardiol. 2015;105(2):1-105.

3. Scirica BM, Libby, P, Morrow DA. ST-Elevation Myocardial Infarction: Pathophysiology and Clinical Evolution in Braunwald's Heart Disease: A Textbook of Cardiovascular Medicine. 11 th ed. Amsterdan:Elsevier; 2019. P.1095-122. 1095-122

4. Ortolani P, A. Marzocchi, C. Marrozzini, Palmerini T, Saia F, Taglieri N, et al. Predictive value of high sensitivity C-reactive protein in patients with ST-elevation myocardial infarction treated with percutaneous coronary intervention. Eur Heart J. 2008;29(10):1241-9

5. Celik T, Iyisoy A, Kursaklioglu H, Turhan H, Kilic S, Kose S, et al. The impact of admission C-reactive protein levels on the development of poor myocardialperfusion after primary percutaneous intervention in patients with acute myocardial infarction. Coron Artery Dis. 2005;16(5):293-9.

6. Ribeiro DRP, Ramos AM, Vieira PL, Menti E, Bordin Jr. OL, de Souza PAL, et al. High-Sensitivity C-Reactive Protein as a Predictor of Cardiovascular Events after ST-Elevation Myocardial Infarction Arq Bras Cardiol. 2014;103(1):69-75.

7. Parenica J, Kala P, Pavkova MG, Tomandl J, Spinar J, Littnerova S ET al. Natriuretic peptides, nitrite/nitrate and superoxide dismutase have additional value on top of the GRACE score in prediction of one-year mortality and rehospitalisation for heart failure in STEMIpatients a more personalized prognosis and therapy to improve the outcome in this population. Prospective and larger cohort studies are needed to confirm these findings and to stablish a cut point for a wider clinical use of this tool. Randomized controlled trials are needed to establish the effectiveness of new treatment regimens guided by biomarkers in STEMI.
- Multiple biomarkers prospective cohort study. Int J Cardiol. 2016;211:96-104.

8. Damman P., Beijk MAM, Kuijt WJ, Verouden NJ, van Gelove N, Henriques JP. Multiple biomarkers at admission significantly improve the prediction of mortality in patients undergoing primary percutaneous coronary intervention for acute ST-segment elevation myocardial infarction. J Am Coll Cardiol 2011;57(1):29-36.

9. Correia LC, Esteves JP. C-Reactive protein and outcomes in acutecoronary syndromes: a systematic review and meta-analysis. Arq Bras Cardiol.2011;97(1):76-85.

10. Milano SS, Moura Júnior OV, Bordin AAS, Marques GL. C-reactive Protein is a Predictor of Mortality in ST-segment Elevation Acute Myocardial Infarction. Int J Cardiol Sci. 2019;32(2)118-124.

11. Killip T 3rd, Kimball JT. Treatment of myocardial infarction in a coronary care unit. A two year experience with 250 patients. Am J Cardiol. 1967;20(4):457-64.

12. Steg P, Dabbous OH, FeldmanLJ, Cohen-Solal A, Aumont MC, Lopez-Sendon J, et al. Determinants and prognostic impact of heart failure complicating acute coronary syndromes: observations from the Global Registry of Acute Coronary Events (GRACE). Circulation.2004;109(4):494-9.

13. Morrow DA, Antman EM, Charlesworth A, Cairns R, Murphy SA, de Lemos JA, et al. TIMI risk score for ST elevation myocardial infarction: a convenient, bedside, clinical score for risk assessment at presentation: an intravenous nPA for treatmet of infracting myocardium early II Trial Substudy. Circulation. 2000;102(17):2031-7. 